\title{
Thin Film Polyamide Membranes with Photoresponsive
} Antibacterial Activity

\author{
Phuoc H. H. Duong, ${ }^{[a, b]}$ Pei-Ying Hong,${ }^{[c]}$ Valentina Musteata, ${ }^{[a]}$ Klaus-Viktor Peinemann, ${ }^{[b]}$ and Suzana \\ $P$. Nunes ${ }^{*[a]}$
}

Abstract: Membranes containing a photosensitizer molecule as part of the selective layer are proposed with demonstrated anti-biofouling activity. For the membrane preparation, mixtures of an aminefunctionalized photosensitizer molecule, (5,10,15,20-(tetra-4aminophenyl)porphyrin) and m-phenylene diamine (MPD) reacted with trimesoyl chloride (TMC) by interfacial polymerization to form thin polyamide films on top of an asymmetric porous support. A highly permeable membrane $\left(35.4 \mathrm{Lm}^{-2} \mathrm{~h}^{-1} \mathrm{bar}^{-1}\right)$ with $99 \%$ rejection of Brilliant Blue R $(826 \mathrm{~g} / \mathrm{mol})$ was obtained using $0.25 \mathrm{wt} \%$ porphyrin and $0.75 \mathrm{wt} \%$ MPD as amine monomers. Under visible light exposure, singlet oxygen $\left({ }^{1} \mathrm{O}_{2}\right)$ is generated in the porphyrin containing-polyamide film, reaching the bacteria in the feed by diffusion and enhancing the biofouling resistance and anti-microbial activity. Anti-biofouling and anti-microbial photoactivity in solution are demonstrated on Staphylococcus aureus at different porphyrin concentrations and light exposure time.

Wastewater treatment has drawn great research efforts due to the lack of clean water in many countries and the need for reuse. Membrane filtration technologies (i.e., microfiltration, ultrafiltration, nanofiltration, ${ }^{[1]}$ reverse osmosis, ${ }^{[2]}$ forward osmosis $^{[3]}$ ) have become the most efficient and effective techniques for contaminated water purification to produce highquality clean water. Thin film composite membranes consisting of a thin polyamide film ${ }^{[4]}$ as a selective skin deposited on an ultrafiltration membrane support are regularly used for membrane-based wastewater treatment because of the high permeability and selectivity properties of the polyamide film. However, membrane fouling still remains one of the major encountered problems of using thin film composite membranes for wastewater treatment because of the high surface roughness and relatively low hydrophilicity of the polyamide film. Fouling can dramatically reduce the membrane performance, increasing energy consumption, and shortening the membrane lifetime. Fouling is caused by the undesirable deposition of inorganic (inorganic fouling or scaling), organic (organic fouling), colloidal/suspended particles (colloidal fouling), and microbial species (biofouling) on the membrane surfaces or into the

[a] Dr. P. H. H. Duong, Dr. V. Musteata, Prof. Dr. S. P. Nunes King Abdullah University of Science and Technology (KAUST), Biological and Environmental Science and Engineering Division (BESE), Thuwal, 23955-6900, Saudi Arabia E-mail: suzana.nunes@kaust.edu.sa

[b] Dr. P. H. H. Duong, Prof. Dr. K. V. Peinemann

King Abdullah University of Science and Technology (KAUST), Advanced Membranes and Porous Materials Center, Thuwal, 239556900, Saudi Arabia

[c] Prof. Dr. P. Y. Hong

King Abdullah University of Science and Technology (KAUST),

Water Desalination and Reuse Center, Thuwal, 23955-6900,

Saudi Arabia

Supporting information for this article is given via a link at the end of the document. membrane pores. Treatment of biofouling is a complicated and costly process because of the fast growth and irreversible adhesion of the microorganisms on the membrane surface. ${ }^{[5]}$

Common strategies to eliminate the biofouling in the membrane filtration process are (i) to reduce the microorganism concentration in the feed by preliminary treatment of the feed to decrease contents of bacteria and nutrients, (ii) to develop novel biofouling resistant membranes, and (iii) to use effective membrane cleaning technique. ${ }^{[6]}$ Conventionally, feed pretreatment and chemical membrane cleaning are commonly used ${ }^{[7]}$ However these methods are costly and cannot eliminate biofouling due to the strong, rapid adhesion and growth of microorganisms. In addition, the presence of aggressive chemicals may cause fast degradation of membranes. The most promising approach for biofouling mitigation would be to avoid the early stages of microbial attachment and growth by chemically tailoring the membrane surfaces. In recent decades, several approaches were investigated, including the use of new polymeric membrane materials, ${ }^{[8]}$ poly(2-hydroxyethyl methacrylate) (PHEMA), ${ }^{[9]}$ silver ions/nanoparticles, ${ }^{[10]}$ copper ions/nanoparticles, ${ }^{[11]} \quad \mathrm{TiO}_{2}$ nanoparticles, ${ }^{[12]}$ polycations,${ }^{[13]}$ zwitterionic polymers, ${ }^{[14]}$ carbon-based materials such as graphene oxide and carbon nanotubes, ${ }^{[15]}$ or nanocomposites. ${ }^{[16]}$ A good alternative for membrane fouling reduction would be the development of novel membranes having antimicrobial photoactivity. This type of membranes should contain photosensitizer molecules on the surface, which produce singlet oxygen $\left({ }^{1} \mathrm{O}_{2}\right)$ under light exposure that may effectively destroy microorganisms.
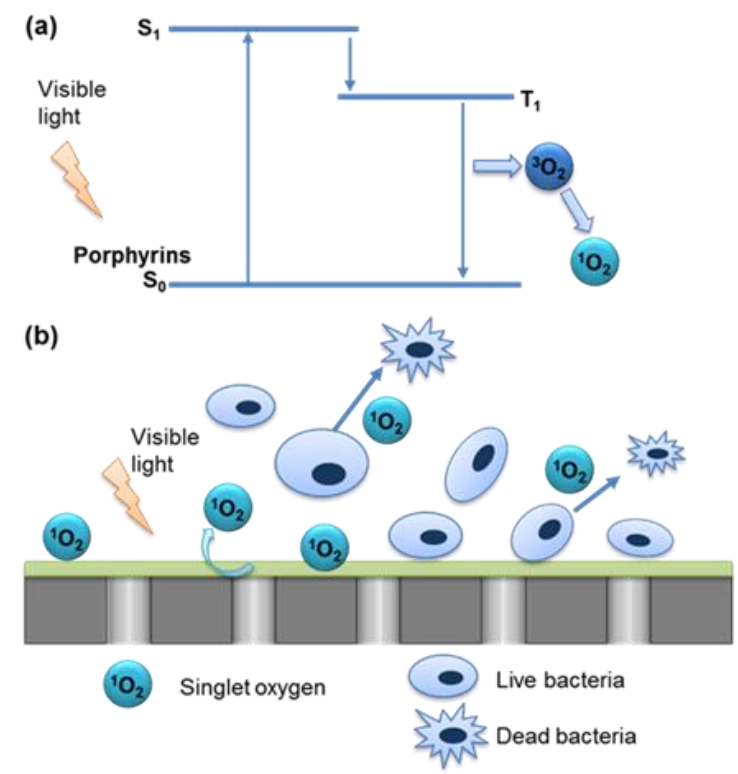

Figure 1. Schematic illustration of (a) the formation of singlet oxygen $\left({ }^{1} \mathrm{O}_{2}\right)$ of porphyrins and (b) antibacterial mechanism of the porphyrin-incorporated membrane. 
Porphyrins are attractive photosensitizer molecules extensively available in nature. Moreover, various types of chemically synthesized and modified porphyrins are welldeveloped and understood. A porphyrin contains a heterocyclic tetrapyrrole unit (called porphine) and different mesosubstituents. Under the irradiation of light, porphyrins absorb energy to reach the $S_{1}$ excited state and then go through an intersystem to the $T_{1}$ excited state and return to the original ground state $\left(\mathrm{S}_{0}\right)$, which transfers the absorbed energy to the triplet oxygen $\left({ }^{3} \mathrm{O}_{2}\right)$ and then generate a large amount of singlet oxygen $\left({ }^{1} \mathrm{O}_{2}\right)$, that effectively kills microorganisms (Figure $1 \mathrm{a}$ ). Porphyrins have been commonly used as photosensitizers to produce singlet oxygen $\left({ }^{1} \mathrm{O}_{2}\right)$ for various photodynamic applications such as cancer therapy ${ }^{[17]}$ and anti-bacterial treatments. ${ }^{[18]}$ Singlet oxygen is not involved in the degradation of polyamide membrane. ${ }^{[19]}$ Hence, the presence of porphyrins in polyamide-based membrane filtration technology would increase the disinfection ability with no harm to the polyamide membrane.

Developing membranes combining the advanced properties of polyamide thin films and porphyrin photosensitizer may provide a promising membrane for wastewater purification. ${ }^{[20]}$ Here we demonstrate a new strategy to develop a highly permeable nanofiltration membrane containing porphyrin to provide antimicrobial photoactivity (Figure $1 \mathrm{~b}$ ). A derivative of porphyrin, 5,10,15,20-(tetra-4-aminophenyl)porphyrin, was polymerized with m-phenylene diamine (MPD) and trimesoyl chloride (TMC) via interfacial polymerization to form a mixedpolyamide film (porphyrin/MPD) as shown in Figure $\mathrm{S} 1$ on a polyetherimide (PEI) ultrafiltration support. Polyamide membranes with varying porphyrin/MPD concentrations were investigated. The membrane fabricated with higher porphyrin concentration exhibits a thinner polyamide film with higher permeance and more significant anti-microbial photodynamic effects on Staphylococcus aureus. The membranes exhibit high water permeance and good selectivity, higher porosity due to the heterocyclic tetrapyrrole unit of porphyrin, biofouling resistance and anti-bacterial effect, given by the photosensitizing property of porphyrin.

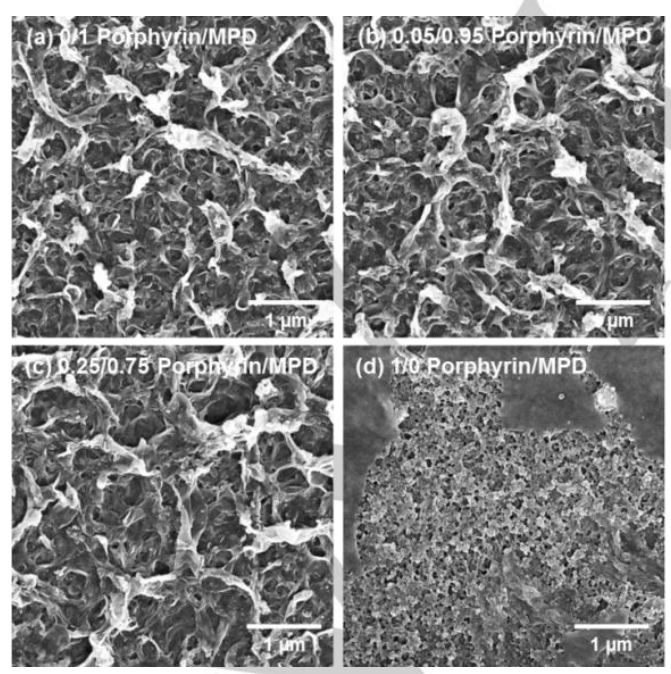

Figure 2. FESEM of porphyrin/MPD polyamide layers on PEI support.

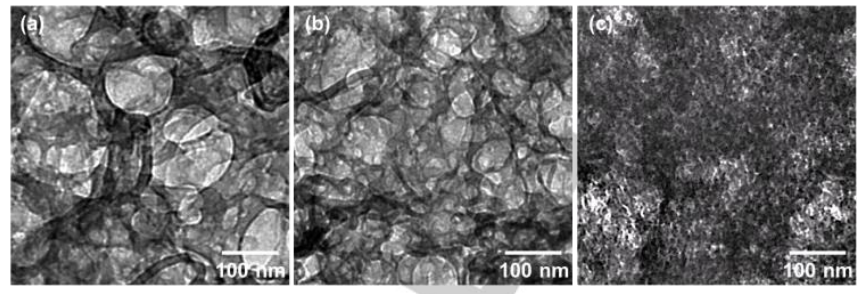

Figure 3. TEM images of free-standing polyamide films, using different porphyrin/MPD concentrations: (a) $0 / 1$, (b) $0.25 / 0.75$, and (c) $1 / 0$.

The surface morphology of polyamide films derived from different porphyrin/MPD concentrations deposited by interfacial polymerization on PEl support is compared in Figure 2. Continuous and defect-free crumpled nodular films were well deposited on the support under fabrication conditions with $0 / 1$, $0.05 / 0.95$, or $0.25 / 0.75(\mathrm{w} / \mathrm{w})$ porphyrin/MPD concentrations. The polyamide film derived from $1 / 0(\mathrm{w} / \mathrm{w})$ porphyrin/MPD has uniform smooth surface but was discontinuous. This is probably due to steric reasons, being difficult to form a continuous film by exclusively reacting the bulky porphyrin blocks with small TMC molecules. The TEM images of polyamide films prepared from $0 / 1-1 / 0(w / w)$ porphyrin/MPD are displayed in Figure 3. The images show defect-free films in sub-micron scale for all fabrication conditions. 0/1 Porphyrin/MPD and 0.25/0.75 porphyrin films have a crumpled nodular structure with larger features, while 1/0 porphyrin/MPD film has a smooth surface with finer structure. This observation is consistent with the FESEM images in Figure 2. No aggregation of porphyrin was detected during the interfacial polymerization. The TEM images in Figure 3 are practically a planar projection of the topography seen by SEM. The morphology change is further confirmed by AFM (Figure S2) and by TEM cross-sections (Figure S3). The surface roughness of $0.25 / 0.75$ porphyrin/MPD is 2 times lower than that of the 0/1 porphyrin/MPD membrane. The morphology and thickness of polyamide films deposited on the support depend on the reaction rate between amines and TMC, and the rate of transfer of amines to the organic phase. During the interfacial polymerization, amines at the interface are transferred to the organic phase and react rapidly with $\mathrm{TMC}$, the film continues to grow by transferring amines into the organic phase by slow diffusion through the initial polyamide film. Rapid transport and reaction might lead to local convection and temperature instability, favoring a rough morphology. Porphyrin is bulkier than MPD, the rate of transfer of porphyrin into the organic phase at the initial interfacial polymerization stage and the diffusion rate of porphyrin through the initial polyamide film would be slower than that of MPD. Therefore, at high concentration of porphyrin, the whole film is smoother (Figure S2) and thinner (Figure S3). A smooth polyamide surface disfavor fouling, since, colloidal/suspended particles, and microorganisms are otherwise prone to accumulate in the interstices of the rough polyamide film. On the other hand a rougher polyamide film has larger surface area and water permeance is expected to be higher.

Figure S4 a displays photographic images of 0/1, 0.05/0.95 and $0.25 / 0.75$ porphyrin/MPD membrane surfaces. The colors change from white for $0 / 1$ porphyrin/MPD to light green for 
0.05/0.95 porphyrin/MPD and dark brown for $0.25 / 0.75$ porphyrin/MPD. It indicates the increasing amount of porphyrin incorporated in the polyamide network. UV-vis spectroscopy was further used to confirm the successful incorporation. Figure S4 b shows remarkably enhanced absorption peaks at $436 \mathrm{~nm}$ for $0.05 / 0.95$ and $0.25 / 0.75$ porphyrin/MPD membranes.

The surface charge of different membranes was compared by zeta potential measurement at different $\mathrm{pH}$. Figure $\mathrm{S} 5$ shows that $0 / 1$ and $0.25 / 0.75$ porphyrin /MPD membranes have negative zeta potential in the $\mathrm{pH}$ range above 4.5. At strong acidic condition, both membranes are positively charged. Compared to $0 / 1$, the $0.25 / 0.75$ porphyrin/MPD surface is less negatively charged. This is due to the presence of porphyrin molecules containing large quantity of non-reacted basic groups $\left(-\mathrm{NH}_{2},-\mathrm{NH}=,-\mathrm{NH}-\right)$.

Table 1. Water permeance and selectivity of polyamide membranes.

\begin{tabular}{llll}
\hline $\begin{array}{l}\text { Porphyrin/MPD } \\
(\mathrm{w} / \mathrm{w}) \text { ratio }\end{array}$ & $\begin{array}{l}\text { Pure Water } \\
\text { Permeance } \\
\left(\mathrm{Lm}^{-2} \mathrm{~h}^{-1} \mathrm{bar}^{-1}\right)\end{array}$ & $\begin{array}{l}\mathrm{PEG}_{1000} \\
\text { Rejection } \\
(\%)\end{array}$ & $\begin{array}{l}\text { Brilliant Blue R } \\
\text { Rejection } \\
(\%)\end{array}$ \\
\hline $0 / 1$ & 14.3 & 23.6 & 99.8 \\
$0.05 / 0.95$ & 15.2 & 23.1 & 99.8 \\
$0.25 / 0.75$ & 35.4 & 19.7 & 99.0 \\
$1 / 0$ & Dis-continuous film was formed \\
\hline
\end{tabular}

Water permeance and selectivity of porphyrin/MPD membranes are shown in Table 1. Increasing porphyrin concentration in the interfacial polymerization formula leads to membranes with higher water permeance. Compared to $0 / 1$ porphyrin/MPD, 0.25/0.75 porphyrin/MPD has higher permeance by a factor higher than 2 . This result contradicts the expectation that lower surface roughness would be associated with lower effective surface area and lower permeance. However the difference in molecular structure is the predominant factor. The heterocyclic tetrapyrrole unit has a higher free volume than the phenyl unit of MPD molecule. In addition, the non-planar structure property of porphyrin could produce less compact polyamide layer compared to polyamide layer derived from MPD only. The presence of the open and non-planar structure of porphyrin increases the free volume and the permeance. Moreover, the $0.25 / 0.75$ porphyrin/MPD polyamide film is thinner than without porphyrin, as shown in Figure S3. The total flux resistance is lower. The membrane selectivity was investigated using a negatively charged dye (Brilliant Blue R) as a textile dye wastewater model and a neutral solute $\left(P E G_{1000}\right)$, both in the nanofiltration range. While all membranes exhibit excellent selectivity towards Brilliant Blue R with a rejection of 99.0 $99.8 \%$, the rejection towards $\mathrm{PEG}_{1000}$ is relatively poor $(19.7 \%$ $23.6 \%$ ), despite similarity in molecular weight. The selectivity of a nanofiltration membrane is determined by size exclusion and charge interaction between solutes and the membrane. The negative charge of Brilliant Blue $R$ prevents the dye from passing through the polyamide membranes due to the mutual electrostatic repulsion. The results show that the effect of the membrane zeta potential is at least as important in this case. Having two-fold higher permeance and negligible sacrifice of rejection the incorporation of porphyrin into polyamide film at a $0.25 / 0.75$ porphyrin/MPD ratio demonstrates superior nanofiltration performance.

The photosensitizing property of mixed-polyamide membranes was investigated using $S$. aureus bacteria. Polyamide membranes prepared from different porphyrin /MPD concentrations were exposed to solutions containing $S$. aureus under visible light irradiation for $16 \mathrm{~h}$ and $36 \mathrm{~h}$, comparing the effects of porphyrin concentration and irradiation time on bacterial photo-inactivation ability of the membranes and biofilm formation on the membrane surfaces. Figure $4 \mathrm{a}$ and $\mathrm{b}$ shows the $S$. aureus viability in solutions after exposure to porphyrin/MPD membranes for $16 \mathrm{~h}$ and $36 \mathrm{~h}$, respectively. Compared to the control membrane (0/1 porphyrin/MPD), higher concentration of porphyrin lead to more significant $S$. aureus photo-inactivation ability by providing lower bacterial viability in the exposed solutions. The bacterial disinfection is stronger with more intense light irradiation (longer irradiation time). Compared to $16 \mathrm{~h}$ irradiation (Figure $4 \mathrm{a}$ ), a longer period of irradiation of $36 \mathrm{~h}$ (Figure $4 \mathrm{~b}$ ) led to significant reduction of $S$. aureus viability, indicating that the bacterial photo-inactivation property of porphyrin/MPD membranes depends on the light irradiation time. Total S. aureus disinfection is observed after $36 \mathrm{~h}$ irradiation, using a $0.25 / 0.75$ porphyrin/MPD membrane.

The formation of biofilm on membrane surfaces after $16 \mathrm{~h}$ and $36 \mathrm{~h}$ light irradiation is shown in Figure S6. More than $50 \%$ surface area of the $0 / 1$ porphyrin/MPD membrane is covered by
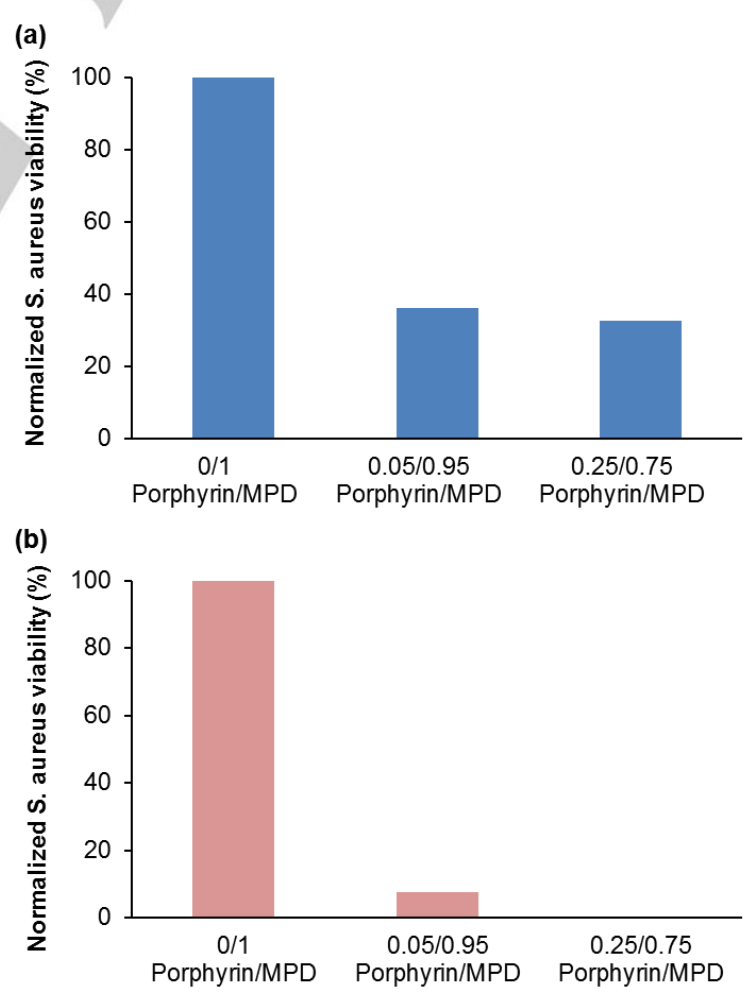

Figure 4. Comparison of $\mathrm{S}$. aureus viability in solution exposed to polyamide membranes with varying concentrations of porphyrin after (a) $16 \mathrm{~h}$ and (b) 36 h light irradiation. 
S. aureus (Figure S6 a). Under the same testing conditions the membranes with porphyrin (Figure S6 b and c) had much lower deposition of $S$. aureus, confirming that porphyrin can reduce $S$. aureus adhesion on the membrane surfaces. The $S$. aureus deposition on the 0/1 porphyrin/MPD membrane increases with longer periods of irradiation for $36 \mathrm{~h}$ (Figure $\mathrm{S} 6 \mathrm{a}$, bottom) However, for $0.05 / 0.95$ and $0.25 / 0.75$ porphyrin/MPD membranes, no significant increase in $S$. aureus deposition were detected even after $36 \mathrm{~h}$ under irradiation. The results indicate that porphyrin containing polyamide membranes exhibit good anti-biofouling properties that are attributed to the photoactivity of porphyrin molecules and the smoother surface of the polyamide film.

The photoactivity of porphyrin in membranes was further evaluated by comparing the $S$. aureus disinfection ability and biofilm formation on 0.05/0.95 porphyrin/MPD membranes kept in dark or under light exposure (Figure S7). Compared to the dark condition, the membranes with light exposure exhibit much lower $S$. aureus deposition. It demonstrates that the effect of light irradiation is significant to provide anti-biofouling properties to porphyrin containing membranes. $S$. aureus viability is reduced from $100 \%$ in dark testing condition to $42.5 \%$ and $0.1 \%$ in $16 \mathrm{~h}$ and $36 \mathrm{~h}$ light testing conditions, respectively. The results show that $0.05 / 0.95$ porphyrin/MPD membranes had a significant photoactivity and biocide effect on $S$. aureus.

In summary, by incorporating porphyrin into the polyamide layer of thin-film composite membranes photosensitizing effects were successfully demonstrated and characterized for the first time. The membranes were fabricated using the simple interfacial polymerization method producing stable photosensitizing nanofiltration membrane. Membranes with varying porphyrin/MPD ratios from $0 / 1$ to $1 / 0$ were fabricated and characterized. The physicochemical properties of the polyamide layer were significantly influenced by the porphyrin/MPD concentration. The SEM and TEM results showed that increasing porphyrin concentration leads to a smoother and thinner polyamide film, which may provide low fouling propensity and less water transport resistance. The bacterial test results showed higher biofouling resistance and more significant bacterial removal from the feed solution, when using the membrane fabricated with higher porphyrin/MPD ratios. It indicates that the obtained porphyrin/MPD membranes can effectively generate singlet oxygen $\left({ }^{1} \mathrm{O}_{2}\right)$ by visible light irradiation to destroy $S$. aureus cells. Compared to the conventional thin film composite membrane (0/1 porphyrin/MPD) the $0.25 / 0.75$ porphyrin/MPD: $0.25 / 0.75$ membrane has superior separation performance (i.e., higher water permeance of 35.4 $\mathrm{Lm}^{-2} \mathrm{~h}^{-1} \mathrm{bar}^{-1}$ and comparable selectivity of $99.0 \%$ rejection of Brilliant Blue R), low membrane biofouling, and > 99.9\% bacterial inactivation of the feed. This technique provides a promising application of new antimicrobial membranes for wastewater treatment. Further development of appropriate module design that allows the exposure of visible light to the membrane surface is necessary to advance the technology.

\section{Supporting Information Summary}

Materials and experimental methods; schematic representation of the synthesis of mixed-polyamide by interfacial polymerization; characteristics of mixed-polyamide membranes; data of photosensitizing property of mixed-polyamide membranes.

\section{Acknowledgements}

This work was funded by King Abdullah University of Science and Technology (KAUST). The authors would like to thank N.L. Le for her help with the PEI membrane preparation.

\section{Conflict of interest}

The authors declare no conflict of interest.

Keywords: biofouling $\bullet$ interfaces $\cdot$ membranes $\cdot$ photoresponsive $\cdot$ porphyrin

[1] a) S. P. Sun, T. A. Hatton, S. Y. Chan, T. S. Chung, J. Membr. Sci. 2012, 401-402, 152-162; b) A. W. Mohammad, Y. H. Teow, W. L. Ang, Y. T. Chung, D. L. Oatley-Radcliffe, N. Hilal, Desalination 2015, 356, 226-254

[2] a) M. A. Al-Obaidi, J. P. Li, C. Kara-Zaïtri, I. M. Mujtaba, Chem Eng. J. 2017, 316, 91-100; b) T. Yu, L. Meng, Q. B. Zhao, Y. Shi, H. Y. Hu, Y. Lu, Water Res. 2017, 113, 1-10.

[3] a) N. Y. Yip, A. Tiraferri, W. A. Phillip, J. D. Schiffman, M. Elimelech, Environ. Sci. Technol. 2010, 44, 3812-3818; b) J. Ren, J. R. McCutcheon, Desalination 2014, 343, 187-193; c) R. C. Ong, T. S. Chung, J. S. de Wit, B. J. Helmer, J. Membr. Sci. 2015, 473, 63-71; d) R. V. Linares, Z. Li, V. Yangali-Quintanilla, Q. Li, J. S. Vrouwenvelder, G. L. Amy, N. Ghaffour, Desalination 2016, 393, 31-38.

[4] M. J. T. Raaijmakers, N. E. Benes, Prog. Polym. Sci. 2016, 63, 86142.

[5] R. Bos, H. C. van der Mei, H. J. Busscher, FEMS Microbiol. Rev. 1999, 23, 179-230.

[6] V. Kochkodan, N. Hilal, Desalination 2015, 356, 187-207.

[7] J. S. Baker, L. Y. Dudley, Desalination 1998, 118, 81-89.

[8] P. H. Duong, S. Chisca, P. Y. Hong, H. Cheng, S. P. Nunes, T. S. Chung, ACS Appl. Mater. Interfaces 2015, 7, 3960-3973.

[9] a) D. Keskin, J. I. Clodt, J. Hahn, V. Abetz, V. Filiz, Langmuir 2014 30, 8907-8914; b) S. Schöttner, H.-J. Schaffrath, M. Gallei, Macromolecules 2016, 49, 7286-7295.

[10] a) D. Y. Zhang, J. Liu, Y. S. Shi, Y. Wang, H. F. Liu, Q. L. Hu, L. Su, J. Zhu, J. Membr. Sci. 2016, 516, 83-93; b) L. F. Villalobos, S. Chisca, H. Cheng, P. Y. Hong, S. Nunes, K. V. Peinemann, RSC Advances 2016, 6, 46696-46701; c) P. Madhavan, P.-Y. Hong, R. Sougrat, S. P. Nunes, ACS Appl. Mater. Interfaces 2014, 6, 1849718501 ; d) S. Zhang, G. Qiu, Y. P. Ting, T.-S. Chung, Colloids Surf. Physicochem. Eng. Aspects 2013, 436, 207-214.

[11] a) S. Asapu, S. Pant, C. L. Gruden, I. C. Escobar, Desalination 2014, 338, 17-25; b) M. Ben-Sasson, K. R. Zodrow, Q. Genggeng, Y. Kang, E. P. Giannelis, M. Elimelech, Environ. Sci. Technol. 2014, 48, 384-393.

[12] S. H. Kim, S. Y. Kwak, B. H. Sohn, T. H. Park, J. Membr. Sci. 2003 211, 157-165.

[13] Y. F. Yang, H. Q. Hu, Y. Li, L. S. Wan, Z. K. Xu, J. Membr. Sci. 2011, 376, 132-141. 
a) S. Zheng, Q. Yang, B. Mi, Appl. Surf. Sci. 2016, 363, 619-626 b) N. Lieu Le, M. Quilitzsch, H. Cheng, P.-Y. Hong, M. Ulbricht, S. P. Nunes, T.-S. Chung, J. Membr. Sci. 2017, 522, 1-11; c) A Vaterrodt, B. Thallinger, K. Daumann, D. Koch, G. M. Guebitz, M. Ulbricht, Langmuir 2016, 32, 1347-1359; d) M. L. Marré Tirado, M. Bass, M. Piatkovsky, M. Ulbricht, M. Herzberg, V. Freger, J. Membr. Sci. 2016, 520, 490-498; e) T. Cai, X. Li, C. Wan, T. S. Chung, J. Membr. Sci. 2016, 497, 142-152; f) D. Zhao, G. Qu, X. Li, C. Wan, K. Lu, T. S. Chung, Water Res. 2016, 104, 389-396. a) F. Perreault, M. E. Tousley, M. Elimelech, Environ. Sci. Technol. Lett. 2014, 1, 71-76; b) H. Li, W. Shi, Q. Du, R. Zhou, H. Zhang, X. Qin, Appl. Surf. Sci. 2017, 407, 260-275. a) A. F. Faria, C. Liu, M. Xie, F. Perreault, L. D. Nghiem, J. Ma, M. Elimelech, J. Membr. Sci. 2017, 525, 146-156; b) S. Zinadini, S. Rostami, V. Vatanpour, E. Jalilian, J. Membr. Sci. 2017, 529, 133141.

a) L. Zhang, J. Lei, F. Ma, P. Ling, J. Liu, H. Ju, Chem. Commun. 2015, 51, 10831-10834; b) S. Su, J. Wang, E. Vargas, J. Wei, R Martínez-Zaguilán, S. R. Sennoune, M. L. Pantoya, S. Wang, J. Chaudhuri, J. Qiu, ACS Biomater. Sci. Eng. 2016, 2, 1357-1366. a) L. Liu, J. Chen, S. Wang, Adv. Healthcare Mater. 2013, 2, 1582 1585; b) A. Hanakova, K. Bogdanova, K. Tomankova, K. Pizova, J. Malohlava, S. Binder, R. Bajgar, K. Langova, M. Kolar, J. Mosinger, H. Kolarova, Microbiol. Res. 2014, 169, 163-170; c) S. Banfi, E. Caruso, L. Buccafurni, V. Battini, S. Zazzaron, P. Barbieri, V. Orlandi, J. Photochem. Photobiol. B: Biol. 2006, 85, 28-38; d) L. Jiang, C. R. R. Gan, J. Gao, X. J. Loh, Small 2016, 3609-3644; e) C. M. B. Carvalho, A. T. P. C. Gomes, S. C. D. Fernandes, A. C. B. Prata, M. A. Almeida, M. A. Cunha, J. P. C. Tomé, M. A. F. Faustino, M. G. P. M. S. Neves, A. C. Tomé, J. A. S. Cavaleiro, Z. Lin, J. P. Rainho, J. Rocha, J. Photochem. Photobiol. B: Biol. 2007, 88, 112-118; f) E. Alves, A. C. Esteves, A. Correia, A. Cunha, M. A. F. Faustino, M. G. P. M. S. Neves, A. Almeida, Photochem. Photobiol. Sci. 2015, 14, 1169-1178; g) G. Rossi, D. Goi, C. Comuzzi, J. Water Health 2012, 10, 390-399.

[19] N. Dam, P. R. Ogilby, Helv. Chim. Acta 2001, 84, 2540-2549.

[20] L. Wen, M. Li, J. B. Schlenoff, J. Am. Chem. Soc. 1997, 119, 77267733. 
Table of Contents

\section{COMMUNICATION}

Photoresponsive membranes prepared by interfacial polymerization, including porphyrin groups. Under visible light, porphyrin generates singlet oxygen, which enhances the biofouling resistance.

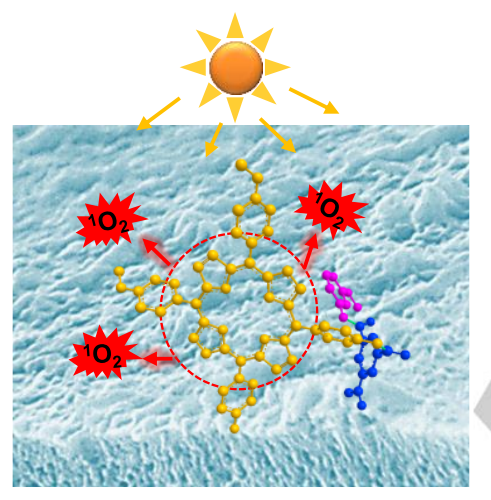

Phuoc H. H. Duong, Pei-Ying Hong, Valentina Musteata, Klaus-Viktor Peinemann, and Suzana P. Nunes*

Page No. - Page No.

Thin Film Polyamide Membranes with Photoresponsive Anti-Bacterial Activity 